\title{
FORMAÇÃO PROFISSIONAL EM EDUCAÇÃO FÍSICA PARA O SE- TOR DA SAÚDE E AS DIRETRIZES CURRICULARES NACIONAIS
}

\author{
Rogério Cruz Oliveira \\ Universidade Federal de São Paulo, Santos, São Paulo, Brasil \\ Douglas Roque Andrade \\ Universidade de São Paulo, São Paulo, São Paulo, Brasil
}

\begin{abstract}
Resumo
O objetivo foi analisar a proposta de extinção do Bacharelado prevista pela Minuta debatida em Audiência Pública no Conselho Nacional de Educação em dezembro de 2015, tendo como eixo argumentativo a necessária formação profissional em Educação Física para o setor da saúde. Para tanto, realizamos uma análise da Minuta, tendo sido considerados todos os trechos relacionados ao termo saúde em ambos os documentos. Concluímos que a formação profissional em Educação Física para o setor da saúde se encontra deficitária frente às demandas do Sistema Único de Saúde. Assim, a proposta de extinção do Bacharelado limitaria ainda mais a formação, pois os desafios à formação em Educação Física e saúde extrapolam os limites de uma única modalidade.
\end{abstract}

Palavras-chave: Educação Física. Formação Profissional. Saúde.

\section{Introdução}

Em 11 de dezembro de 2015 a comunidade acadêmica da Educação Física (EF) foi convidada a uma Audiência Pública no Conselho Nacional de Educação (CNE) para se pronunciar sobre uma Minuta de Projeto de Resolução sobre as Diretrizes Curriculares Nacionais (DCN's) para seus cursos de graduação e recomendava a extinção da formação do bacharel. Não obstante a isso, curioso foi o convite ser enviado aos coordenadores de curso de graduação em EF somente em 30/11/2015, invalidando uma discussão qualificada no interior das instituições formadoras. Nesse sentido, a Audiência consistiu num arrolamento de argumentos contrários e favoráveis a extinção do bacharelado que, no máximo, contribuiu para a conclusão de que era necessário maior tempo de diálogo para que o debate pudesse amadurecer.

Nesse interim, o ano de 2016 se iniciou com vários fóruns agendados para que a comunidade acadêmica se articulasse na análise da referida Minuta. Num destes eventos, realizado em 11/03/2016 na Escola de Educação Física da Universidade de São Paulo, estiveram presentes representantes das instituições de ensino superior públicas do estado, o Conselho Regional de Educação Física - Regional 4, a Associação Brasileira para o Ensino da Educação Física para a Saúde (ABENEFS), bem como o Prof. Dr. Luiz Roberto Liza Curi (Presidente da Comissão da Câmara de Educação Superior do Conselho Nacional de Educação que tratava a referida visão) afirmou que a Minuta era um documento superado e que aguardaria novas propostas, assumindo o compromisso de organização de fóruns regionais. Entretanto, até o momento (outubro de 2016), a pauta não reapareceu. 
Frente ao exposto, nos parece plausível abordar a temática sob o ponto de vista da formação em saúde, considerando que se trata de temática que, embora pertinente, tem ocupado tímido espaço nas argumentações apresentadas.

Assim, o objetivo desse texto é analisar a proposta de extinção do Bacharelado prevista pela Minuta debatida em Audiência Pública no Conselho Nacional de Educação em dezembro de 2015, tendo como eixo argumentativo a necessária formação profissional em EF para o setor da saúde.

Para tanto, analisaremos a Minuta e as DCN's (Resolução 7/2004), enfocando os trechos relacionados ao termo saúde que aparecem nos documentos e o que isso impacta na formação do profissional de EF para atuação no setor da saúde. Discorreremos ainda sobre o Núcleo de Apoio à Saúde da Família (NASF) e o Programa Academia da Saúde (PAS) e os desafios para o campo da formação profissional em EF no setor da saúde como exemplos.

\section{As Diretrizes Curriculares Nacionais e a formação profissional em EF para o setor da saúde}

Um dos marcos legais para a formação profissional em EF para o setor da saúde foi a Resolução 7 de 2004, que instituiu as DCN's para os cursos de graduação em EF, em nível superior de graduação plena. A Resolução antecessora (03/1987) não fazia nenhuma menção à saúde, se pronunciando apenas sobre 2 campos de atuação: escolar (licenciatura) e não escolar (bacharelado).

Em nosso entendimento, alguns fatores foram determinantes, dentre os quais a constatação de Bagrichevsky e Estevão (2008) de que na década de 1980 nenhuma publicação na área de EF fez menção ao amplo debate sobre saúde. Para os autores, a produção de conhecimento nessa época não se atentou

[...] para os questionamentos e premissas do Movimento Sanitarista na América Latina e no Brasil que atribuíam à saúde - entendida como fenômeno complexo - um significado resultante das condições de vida ofertadas pelo Estado à população; isto é, alimentação, moradia, (des)emprego e condições dignas de trabalho, educação, nível de renda, de acesso aos (e qualidade dos) serviços de saúde. Esses aspectos, proficuamente explorados por muitos pesquisadores em obras de referência da Saúde Pública [...] sequer [sic] freqüentavam os círculos de debate na produção acadêmica da EF no período (BAGRICHEVSKY e ESTEVÃO, p.135).

Outro fato é que somente em 1990 o Sistema Único de Saúde (SUS) foi regulamentado, tendo pronunciado que

A saúde tem como fatores determinantes e condicionantes, entre outros, a alimentação, a moradia, o saneamento básico, o meio ambiente, o trabalho, a renda, a educação, o transporte, o lazer e o acesso aos bens e serviços essenciais; os níveis de saúde da população expressam a organização social e econômica do País (grifo nosso).

Pode-se afirmar que o fato do lazer surgir na Lei como condicionante ampliou o diálogo entre a EF e a saúde ${ }^{1}$, apesar de tímido, permitiu novos olhares para o campo da formação. Isso porque o lazer, embora originário das ciências humanas e sociais, tem sido tradicional-

\footnotetext{
${ }^{1}$ É interessante que esse fato e as reflexões do campo do lazer também não se aproximaram do debate do setor da saúde.
} 
mente abordado nos currículos dos cursos de EF como uma das possibilidades de campo de atuação.

Além disso, é somente em 1997, por meio da Resolução 218, que a EF passa a ser considerada uma profissão da saúde, embora, na mesma esteira de Souza Neto et al. (2004), entendemos que no campo da legitimidade a EF dialoga com a saúde desde o século XIX, uma vez que os argumentos higienistas tiveram estreita ligação com a construção do campo acadêmico. No entanto, em que pese os enlaces legítimos da EF com a saúde desde sua origem no Brasil, foi na década de 1990 do século XX que os atos legais selaram de vez a relação entre as duas áreas e causaram impacto na formação profissional.

A década de 1990 também foi marcada pela regulamentação da profissão de EF, que, por meio da Lei 9696/1998 criou os respectivos Conselho Federal e Conselhos Regionais de EF. Embora a Lei não faça nenhuma menção à saúde há referência à atividade física, que, em 2013, por meio da Lei 12.864, foi explicitada como um condicionante de saúde (BRASIL, 2013a).

Os fatos descritos acima influenciaram na promulgação de novas DCN's em 2004, que, pela primeira vez contemplou a saúde. Passamos a analisar.

Primeiramente, não foi possível comparar a Resolução 7/2004 e a Minuta, pois, no que se refere à saúde, não há alteração de conteúdo na redação dos dois documentos. De antemão, isso já demonstra um limite, pois desconsidera o debate acumulado no cenário da saúde nacional dos últimos 11 anos que induzem mudanças para a formação profissional de EF. Para fins desse texto, utilizaremos o texto da Minuta para análise.

A primeira vez que o termo saúde aparece no documento é no Artigo $2^{\circ}$ que trata da conceituação de EF:

A Educação Física é uma área de conhecimento e de intervenção acadêmicoprofissional que tem como objeto de estudo e de aplicação o movimento humano, com foco nas diferentes formas e modalidades do exercício físico, da ginástica, do jogo, do esporte, da luta/arte marcial, da dança, nas perspectivas da prevenção de problemas de agravo da saúde, promoção, proteção e reabilitação da saúde, da formação cultural, da educação e da reeducação motora, do rendimento físico-esportivo, do lazer, da gestão de empreendimentos relacionados às atividades físicas, recreativas e esportivas, além de outros campos que propiciem ou venham a propiciar a prática de atividades físicas, recreativas e esportivas (grifo nosso).

A maioria das DCN's dos cursos da área da saúde reforçou a necessidade de articulação entre a educação superior e o sistema de saúde vigente, com o objetivo de que a formação geral e específica dos egressos privilegiasse a ênfase na promoção, prevenção, recuperação e reabilitação da saúde, de forma que o conceito de saúde e os princípios do SUS se constituíssem em aspectos fundamentais a serem considerados nessa articulação. $\mathrm{Na}$ área de EF manteve-se a ênfase na promoção, prevenção, recuperação e reabilitação da saúde, mas houve afastamento do SUS. Para Bagrichevsky e Estevão (2008), isso é fruto de histórico descompasso epistemológico, aliada à não participação ativa nos principais fóruns e instâncias deliberativas no setor de saúde, tais como a Associação Brasileira de Saúde Coletiva e Rede Unida ${ }^{2}$, fazendo com que a EF seja deficitária na compreensão da Saúde Pública ${ }^{3}$.

Entretanto, não se trata de um problema exclusivo da EF. Para Ceccim e Feuerwerker (2004), uma das áreas menos problematizadas na formulação de políticas públicas do SUS é a

\footnotetext{
${ }^{2}$ A Rede Unida tem como objetivo comum o desenvolvimento de Recursos Humanos em Saúde (BAGRICHEVSKY e ESTEVÃO, 2008).

${ }^{3}$ Em 2007 foi criada a Sociedade Brasileira de Atividade Física e Saúde, sendo uma de suas finalidades promover e apoiar procedimentos direcionados ao aperfeiçoamento profissional-científico de seus afiliados.
} 
da formação, embora Haddad et al. (2010, p.384) afirmem que "O tema recursos humanos ocupa a agenda da política de saúde como ponto nodal para a implementação dos sistemas nacionais de saúde". Não obstante a isso, uma das facetas comuns a todas as áreas de formação para a saúde é signatária de uma tradição centrada na doença, como é possível perceber também no trecho da Minuta, quando o mesmo aborda a saúde em termos de "prevenção de problemas de agravos à saúde". Para Carvalho e Ceccim (2013, p.137), "O ensino de graduação, na saúde, acumulou uma tradição caracterizada por um formato centrado em conteúdos e numa pedagogia da transmissão [...]" orientada pela doença e pela reabilitação, não tendo uma orientação integradora entre ensino e trabalho que estejam voltados à integralidade e/ou para o enfrentamento das necessidades de saúde da população. Embora pertinente, trata-se de uma discussão não assimilada na Minuta e limita à compreensão de como deve se dar a formação para a atuação no setor da saúde.

No parágrafo único do artigo $3^{\circ}$ da Minuta há o indicativo do foco a ser evidenciado na formação do egresso:

$\S$ único. Os cursos de Educação Física deverão qualificar os egressos para analisar criticamente a realidade social, para nela intervir acadêmica e profissionalmente por meio das diferentes manifestações e expressões do movimento humano, visando à formação, à ampliação e ao enriquecimento cultural das pessoas, para aumentar as possibilidades de adoção de um estilo de vida fisicamente ativo e saudável (grifos nossos).

Tal trecho remete a uma formação em EF para o setor da saúde que seja conivente das nuances pós-modernas da atualidade. A ideia de adoção de um estilo de vida remete à perspectiva de que isso é possível escolher. Castiel e Silva (2006) nos obrigam a refletir sobre o caráter individualista do termo:

[...] as pessoas, independentemente de seus contextos socioeconômicos e culturais e, portanto, das margens de escolha em seus modos de vida, teriam a responsabilidade de se exercitarem para viverem mais tempo e com melhor qualidade de vida (p.80-81).

Trata-se, nesse sentido, de dirigir a formação em EF numa perspectiva contrária à integralidade, universalidade e equidade propostos pelo SUS. Ainda em Castiel e Silva (2006, p.84), como pensar em estilos de vida em contextos de miséria ou a grupos sociais onde as margens de escolha praticamente inexistem? "[...] nessas circunstâncias, o que há são estratégias possíveis de sobrevivências, muitas vezes sem margem de escolha”. Em síntese, há um claro limite de compreensão da formação em EF para o setor da saúde que, para além da necessidade de superação desse quadro, necessita se apropriar dos pressupostos relacionados às demandas e necessidades em saúde, da criação de vínculo com os usuários dos serviços de saúde e da determinação social das escolhas das pessoas, a relevância de se considerar os territórios nos quais a saúde é produzida e os projetos terapêuticos singulares propostos pelas equipes multidisciplinares, incluindo a EF.

Por fim, são descritas competências e habilidades que fazem menção à saúde e que devem constituir a concepção nuclear dos projetos pedagógicos de formação do graduado em EF:

III - intervir acadêmica e profissionalmente de forma deliberada, adequada e eticamente balizada nos campos da prevenção, promoção, proteção e reabilitação da saúde, da formação cultural, da educação e reeducação motora, do rendimento físico-esportivo, do lazer, da gestão de empreendimentos re- 
lacionados às atividades físicas, recreativas e esportivas, além de outros campos que oportunizem ou venham a oportunizar a prática de atividades físicas, recreativas e esportivas; IV - participar, assessorar, coordenar, liderar e gerenciar equipes multiprofissionais de discussão, de definição e de operacionalização de políticas públicas e institucionais nos campos da saúde, do lazer, do esporte, da educação, da segurança, do urbanismo, do ambiente, da cultura, do trabalho, dentre outros; V - diagnosticar os interesses, as expectativas e as necessidades das pessoas (crianças, jovens, adultos, idosos, pessoas portadoras de deficiência, de grupos e comunidades especiais) de modo a planejar, prescrever, ensinar, orientar, assessorar, supervisionar, controlar e avaliar projetos e programas de atividades físicas, recreativas e esportivas nas perspectivas da prevenção, promoção, proteção e reabilitação da saúde, da formação cultural, da educação e reeducação motora, do rendimento físico-esportivo, do lazer e de outros campos que propiciem ou venham propiciar a prática de atividades físicas, recreativas ou esportivas, desenvolvidos nos âmbitos de instituições educacionais, de atendimento à saúde e nas demais instâncias sociais pertinentes; VI - conhecer, dominar, produzir, selecionar, e avaliar os efeitos da aplicação de diferentes técnicas, instrumentos, equipamentos, procedimentos e metodologias para a produção e a intervenção acadêmicoprofissional em Educação Física nos campos da prevenção, promoção, proteção e reabilitação da saúde, da formação cultural, da educação e reeducação motora, do rendimento físico-esportivo, do lazer, da gestão de empreendimentos relacionados às atividades físicas, recreativas e esportivas, além de outros campos que propiciem ou venham a propiciar a prática de atividades físicas, recreativas e esportivas [...] (grifos nossos).

Em que pese à presença de verbos que remetem à consideração do contexto nos processos de intervenção em saúde, como "diagnosticar", "avaliar" e "participar", alinhados ao SUS, fica o questionamento: A licenciatura como única modalidade de formação (artigo 7 da Minuta), teria condição de abranger essa demanda, tendo ainda que obedecer a Resolução $\mathrm{CNE} \mathrm{n}^{\circ}$ 2/2015, específica para as licenciaturas, e a Resolução CNE/CES nº/2009, voltada à questões comuns de 9 cursos de bacharelado da área da saúde, sendo a EF uma delas? Se considerarmos alguns estudos sobre formação em EF e saúde desenvolvidos após a Resolução 7/2004 a compreensão é a de que isso tem sido um problema de complexa superação.

Anjos e Duarte (2009) investigaram currículos de graduação em EF, os resultados apontaram que: não há direcionamento dos cursos de graduação para a área da saúde; as disciplinas que abordam a temática possuem natureza prescritiva e curativa, e; o estágio no serviço de saúde não é previsto.

Brugnerotto e Simões (2009) investigaram o conceito de saúde presente nos currículos de formação em EF em instituições paranaenses, identificaram a predominância de uma concepção restrita de saúde nos cursos analisados. O conceito de saúde predominante esteve relacionado fortemente, quando não exclusivamente, com a perspectiva biológica, não considerando a interrelação da saúde com as ciências humanas. Para os autores, tal resultado remete a preocupação de que a justificativa de intervenção em EF limite-se apenas à "[...] 'faça atividade física e ganhe saúde' [...]" (p. 162).

Pasquim (2010) investigou sobre as concepções de formação em saúde presentes na graduação em EF de duas instituições públicas de ensino superior paulistas. $\mathrm{O}$ autor entrevistou os professores responsáveis pelas disciplinas de Saúde Coletiva e Saúde Pública de dois cursos de graduação, bem como analisou as ementas das disciplinas. Os resultados apontaram que a Saúde Coletiva é marginalizada nos cursos, estando isoladas em disciplinas com peque- 
na carga horária. Para o autor, o conhecimento abordado dessa forma parece não causar impacto na formação profissional em EF.

Costa et al. (2012) investigaram a formação profissional em Saúde Pública/Coletiva dos profissionais de EF, verificou-se que a maioria das instituições não apresenta disciplinas abordando o conteúdo de Saúde Pública/Coletiva. Os autores também afirmaram que foram os bacharelados que mais apresentaram abordagem de tal conteúdo em seus currículos.

Já em Falci e Belisário (2013), analisaram a formação em EF para atuação na atenção primária à saúde, uma das conclusões é a de que a EF ainda possui limitações, que, de acordo com os voluntários do estudo, uma delas consiste na ênfase dada ao treinamento esportivo na formação.

Pizani e Rinaldi (2014) estudaram como os cursos de EF em licenciatura e bacharelado paranaenses se caracterizaram após a promulgação das DCN's em 2004, os resultados enfatizam que a saúde e o treinamento esportivo são os fios condutores dos cursos de bacharelado a partir do discurso dos coordenadores de curso, embora isso não tenha sido tão evidente quando se analisou os projetos pedagógicos dos cursos.

Santiago, Pedrosa e Ferraz (2016) analisaram as DCN's e o Projeto Político Pedagógico em EF de uma universidade do nordeste brasileiro, existem inúmeros elementos de fragilidade na formação que subsidiariam uma melhor atuação em saúde, principalmente relacionados à oferta de disciplinas ou espaços no currículo para a apropriação deste debate.

Frente ao exposto, pode se afirmar que há um quadro problemático quando se observa a formação em EF para o setor da saúde. Ainda que o curso de bacharel possua limites que urgem ser debatidos, não é a unificação da formação que superaria a problemática exposta. Ressaltamos que não é do nosso conhecimento um movimento similar nos demais cursos de saúde a busca pela extinção de uma das modalidades de formação.

No limite podemos nos questionar quais os melhores caminhos para a superação da problemática. Ou melhor, se existe apenas um caminho? Numa tentativa de resposta recorreremos à criação do NASF em $2008^{4}$ e do PAS em 2011 ${ }^{5}$. Em nosso entendimento, esses dois fatos pós-DCN’s e pré-Minuta pressupõe desafios que podem nortear a formulação de uma melhor diretriz de formação em EF para o setor da saúde.

\section{NASF e PAS: desafios para a uma diretriz de formação em EF para o setor da saúde}

Na esteira do trabalho em saúde na Atenção Básica (AB), a EF foi inserida, pela Portaria 154/2008, no NASF, que é composto por mais 12 profissões, e atua junto às equipes de Saúde da Família. Estes fatos denotam um movimento importante na área para afirmação do papel do profissional de EF, pois consolidam as potencialidades deste profissional na área da saúde na medida em que o reconhecem. Entretanto, considerando a Política Nacional de Promoção da Saúde, a Política Nacional da AB e as responsabilidades dos profissionais de saúde do NASF que reforçam a importância da atividade física e das práticas corporais, fica evidente que a formação em EF está distante das questões como acolhimento, trabalho intersetorial,

\footnotetext{
${ }^{4}$ O NASF foi criado pela Portaria 154/2008 com o objetivo de apoiar a consolidação da Atenção Básica (AB) no Brasil. Atualmente, é regulamentado pela Portaria 2488/2011 e outras 3 Portarias complementares: 3124/2012, $548 / 2013$ e 562/2013.

${ }^{5}$ Existem 2 outros programas que impactam a formação em EF para o setor da saúde que não serão aprofundados devido aos limites impostos à um texto como esse, a saber: o Programa de Educação pelo Trabalho para a Saúde, articulado como uma das ações intersetoriais direcionadas para o fortalecimento de áreas estratégicas para o SUS; o Programa Nacional de Reorientação da Formação Profissional em Saúde, que visa a integração ensinoserviço no intuito de reorientar a formação dos profissionais da área da saúde com ênfase na AB. Sem esquecer, é claro, da existência, desde 2005, dos Programas de Residência Multiprofissionais, que, ao ser oferecidos como pós-graduação lato sensu, voltada para a educação em serviço destinada às áreas profissionais da saúde, demandam à graduação a formação de um profissional de saúde que esteja alinhado ao SUS e a AB.
} 
gestão integrada, participação, projeto terapêutico singular, matriciamento, trabalho interprofissional, empoderamento, autonomia, dentre outras que cercam a área do cuidado em saúde. Vejamos.

O NASF sem dúvida contribui para a ampliação da inserção do profissional de EF no setor saúde, porém é importante reforçar que a promoção da atividade física nesse setor antecede a presença e estabelecimento da EF como profissão. Diversas iniciativas foram desencadeadas pelo Ministério da Saúde antes de 2008 (ANDRADE, 2011) e que também estimularam a inclusão dos profissionais de $\mathrm{EF}$, especialmente na $\mathrm{AB}$.

Santos e Benedetti (2012) apontaram que o coeficiente de profissional de EF por população coberta pela Saúde da Família no Brasil foi aproximadamente 1 para 100.000 pessoas e que a área era a quinta profissão mais contratada. Ainda que essa cobertura seja baixa, com a expansão do NASF em todo território nacional teremos mais profissional de EF entrando nesse cenário. As autoras ainda enfatizam que, apesar de estar vinculada a prevenção e promoção da saúde, a EF possui pouca experiência nos serviços públicos, enfrentando assim um desafio para definição do seu papel profissional e competências necessárias para atuação junto ao SUS.

Souza e Loch (2011) apontaram que os profissionais de EF que atuavam no NASF do Norte do Paraná não referiram aproximação com a área de saúde pública na graduação e descreveram que as atividades realizadas estiveram concentradas em atividades de grupos específicos, contribuindo para a baixa cobertura e indicando pouco conhecimento de uma abordagem mais ampla de saúde. Os autores também reforçaram que a divisão das formações (licenciatura e bacharelado) poderia contribuir para uma formação mais adequada para esse trabalho.

Coutinho (2011), ao estudar as competências do profissional de EF para a atuação na $\mathrm{AB}$, identificou 58 delas em três dimensões indissociáveis entre conhecimento, habilidades e atitudes. Além disso, identificou que a falta de aproximação dos profissionais com a prática profissional em saúde, além de ser um enorme desafio, pode afastá-los desse setor, devido ao desconforto, estranheza e insegurança pelo fato da proximidade com conceitos e princípios que não lhe são familiares. Por outro lado, se trata de um terreno de possibilidades, inclusive na produção de novos conhecimentos, habilidade e atitudes (COUTINHO, 2011).

Já a criação do PAS em 2011 foi mais uma janela de oportunidade para a inserção do profissional de EF no SUS, mesmo com a ampliação do programa que em sua criação era especificamente para a promoção da atividade física e em 2013 passa a ter como objetivo principal contribuir para a promoção da saúde e produção do cuidado e de modos de vida saudáveis da população a partir da implantação de polos com infraestrutura e profissionais qualificados (BRASIL, 2013d). Em suas diretrizes, o PAS configura-se como uma das redes de atenção à saúde ligado à promoção da saúde, estabelecendo-se como espaço de produção, ressignificação e vivência de conhecimentos favoráveis à construção coletiva de modos de vida saudáveis. Para tanto, os princípios do PAS se firmam na participação popular e construção coletiva de saberes e práticas em promoção da saúde, primado pela intersetorialidade, interdisciplinaridade, integralidade, intergeracionalidade e territorialidade.

Considerando a situação atual da implantação dos polos do PAS no Brasil (SÁ et al, 2016) e suas diretrizes e princípios do programa identificamos, assim como no NASF, o distanciamento que a área de EF apresenta em relação as essas áreas que também estão alinhadas as políticas de saúde do nosso país. O fato de que sempre nos considerarmos da área da saúde não foi suficiente para que o processo de formação se aproximasse dos princípios da promoção da saúde que norteiam o setor da saúde. Para Ferla, Bueno e Souza (2013), isso é fruto de uma abordagem hegemonicamente biomédica sobre a saúde desenvolvida na formação inicial que, consequentemente, mantém os estudantes na lógica restrita da prescrição de exercícios físicos, quase como um receituário. Guarda et al. (2015) 
identificaram, entre os profissionais de EF que atuavam no PAS na região metropolitana do Recife, a necessidade de maior investimento na formação inicial e em serviço, de modo a qualificar as atividades nos polos e no território. Os profissionais entrevistados no estudo estavam formados a mais de cinco anos e não cursaram disciplinas de saúde coletiva. Seus processos de trabalho caracterizam-se pela precariedade do material utilizado nas aulas de ginástica, participação ineficiente da coordenação do programa no planejamento, execução e avaliação das ações e dificuldades de articular as atividades do programa às demais ações e serviços na rede de atenção primária.

Nesse interim, fica evidente que implantação do NASF e do PAS criou um enorme desafio a ser enfrentado na formação para a atuação no setor saúde. Considerando o amplo campo de atuação do profissional de EF, a questão é como potencializar a formação para a atuação nesse setor garantindo uma formação adequada também para outras áreas (educação, esporte, lazer etc.), como requer a Minuta com a extinção do Bacharelado. Em se tratando de saúde

[...] a discussão sobre a formação profissional para o trabalho no SUS deve ser constante, porém, essa discussão deve ser pautada pela aproximação de saberes, avançando para a interdisciplinaridade e não para o rompimento entre diferentes concepções ideológicas ou partidárias, pois o complexo campo da saúde não pode ser reduzido a esta ou àquela concepção ou área do conhecimento (ANDRADE et al., 2014, p.103).

Reconhecemos que uma resposta a demanda na melhora na formação do profissional de EF, considerando os desafios postos pelo NASF e PAS, foi a criação da ABENEFS ${ }^{6}$, que se justificou por 4 motivos: 1- Atender princípios ideológicos, legislativos e políticos; 2- Adequar o perfil docente na formação inicial; 3- Adequar a formação e a atuação profissional com a organização do SUS, e; 4- Incentivar criação de cursos em EF com eixos na integralidade na formação e na atenção à saúde (FONSECA, 2011). Trata-se de um horizonte promissor, já que a associação possui cadeira no Fórum Nacional de Educação das Profissões na Área da Saúde, que, criado em 2004, possui inserção nos Ministérios da Educação e Saúde em assuntos pertinentes à formação.

Em termos de cursos de graduação, têm-se no Estado de São Paulo, ao menos dois cursos de bacharelado em EF que apresentam em seus projetos políticos pedagógicos a intencionalidade de preparar melhor para a atuação na área da saúde. O curso da Escola de Artes, Ciências e Humanidades da Universidade de São Paulo (EACH-USP) e o da Universidade Federal de São Paulo - Campus Baixada Santista (UNIFESP-BS).

O primeiro oferece disciplinas que apresentam potencial contribuição para a atuação no campo da saúde pública e coletiva: Fundamentos da EF e Saúde, Epidemiologia da Atividade Física, Gestão e Políticas Públicas em Atividade Física e Saúde e Saúde Pública e Promoção da Saúde (obrigatórias) e Estudos Avançados em Atividade Física (optativa/eletiva). Na EACH-USP há uma indicação para que os alunos cursem a disciplina interdepartamental "Práticas, formação e educação interprofissional em saúde" como optativa livre na Escola de Enfermagem - USP. Os alunos da EACH possuem um ciclo básico com a disciplina de resolução de problemas I e II que também contribuem para uma formação mais ampla com valorização da formação interprofissional (FLORINDO et al., 2012; ANDRADE et al., 2014).

No curso da UNIFESP-BS a concepção da formação profissional em EF obedece ao Projeto Pedagógico Institucional de natureza interdisciplinar (integração das disciplinas) e interprofissional (trabalho em equipe) conjugado com outros 5 cursos: Fisioterapia, Nutrição,

\footnotetext{
${ }^{6}$ Recentemente, a associação publicou um manifesto apresentando como diversos segmentos podem colaborar para uma formação inicial em EF mais voltada às necessidades do setor saúde.
} 
Psicologia, Serviço Social e Terapia Ocupacional. Ao longo da formação, os alunos de todos os cursos cumprem juntos, na mesma sala de aula, aproximadamente $30 \%$ da carga horária em 3 eixos comuns: $O$ ser humano em sua dimensão biológica; $O$ ser humano e sua inserção social, e; Trabalho em Saúde. O curso, criado em 2006, almeja uma formação profissional que habilite o egresso às demandas de atuação do sistema de saúde (FERREIRA et al., 2013).

Ou seja, em termos de experiências de formação em EF para o setor da saúde, essas duas experiências nos inspiram ao debate pretendido neste ensaio.

\title{
Conclusão: pela manutenção do Bacharelado e novos debates
}

Concluímos assim que a formação profissional em EF para o setor da saúde se encontra deficitária frente às demandas do SUS. No entanto, a proposta de extinção do Bacharelado limitaria ainda mais a formação, pois os desafios à formação em EF e saúde extrapolam os limites de uma única modalidade.

Nesse sentido, parece oportuno apontarmos que a grande questão formativa que poderia dirigir o debate daqui em diante esteja centrada não na extinção de uma ou outra modalidade, mas como ambas (licenciatura e bacharelado) podem atender as demandas da atuação profissional dos diversos setores que se propõe a formar.

Nesse contexto, é notória a discussão acumulada no campo da EF escolar, que, mesmo passível de certos reducionismos, a garante como um componente curricular da educação básica, permitindo solidez e identidade à formação do licenciado. Por outro lado, a formação na modalidade bacharelado carece em geral de uma discussão ampliada que busque qualificá-la e em particular, para o setor da saúde, que atenda as demandas do SUS. Sem dúvida, aí reside uma promissora perspectiva.

\section{PROFESSIONAL TRAINING IN PHYSICAL EDUCATION RELATED TO HEALTH SECTOR AND THE NATIONAL CURRICULUM GUIDELINES}

\begin{abstract}
The aim was to analyze the purpose about Bachelor professional degree modality extinction discussed in Public Meeting in the National Education Council in December 2015 from a Draft, considering the assumptions about professional training in Physical Education related to Health sector. For this, the Draft were analyzed, considering all text parts related to word "health". In conclusion, the professional training in Physical Education related to Health sector was considered deficient for demands from Unified Health System. Thus, the pourpose about Bachelor professional degree modality extinction is restricted due to the challenges to professional training in Physical Education related to Health extrapolate the concept of a unique degree.
\end{abstract}

Keywords: Physical Education and Training. Professional Training. Health.

\section{FORMACIÓN PROFESSIONAL EN EDUCACIÓN FÍSICA EN LO QUE SE REFIE- RE AL SECTOR DE LA SALUD Y LAS DIRECTRICES CURRICULARES NACIO- NALES}

\section{Resumen}


El objetivo del estudio fue analizar la rescisión propuesta de la extinción de la Licenciatura previsto por Minuta debatida en audiencia pública en el Consejo Nacional de Educación en diciembre de 2015, con el argumento de la necesaria formación en Educación Física para el sector de la salud. Para tanto, realizamos um análisis de la Minuta y considerados todos los trechos relacionados al término salud. Concluimos que la formación profesional en Educación Física para el sector de la salud se encuentra deficitaria ante las demandas del Sistema Único de Salud. Así, la propuesta de extinción de la Licenciatura es limitada, porque los desafíos para la formación en Educación Física y salud ultrapasan los límites de una única formación.

Palabras clave: Educación Física. Formación Profesional. Salud.

\section{Referências}

ANDRADE, D.R. Políticas recentes de promoção da atividade física no setor da saúde no Brasil. Revista Corpoconsciência, Santo André, v.15, n.2, p.2-6, jul/dez, 2011.

ANDRADE, D.R. et al. Formação do bacharel em educação física frente à situação de saúde no Brasil. In: BENEDETTI, T.R.B. (Orgs.). A formação do profissional de Educação Física para o setor saúde. Florianópolis: Postmix, 2014. p.87-107. Disponível em: http://nupaf.ufsc.br/files/2009/09/LIVRO-FINAL-FINAL.pdf. Acesso em 08 jun. 2016.

ANJOS, T.C.; DUARTE, A.C.G.O. A educação física e a estratégia de saúde da família: formação e atuação profissional. Physis - Revista de Saúde Coletiva, Rio de janeiro, v.19, n.4, p. 1127-1143, ago., 2009.

BAGRICHEVSKY, M.; ESTEVÃO, A. Perspectivas para a formação profissional em Educação Física: o SUS como horizonte de atuação. Arquivos em Movimento, Rio de Janeiro, v.4, n.1, p.128-143, jan./jun., 2008.

BRASIL. Conselho Nacional de Educação. Câmara de Educação Superior. Minuta de Projeto de Resolução para audiência pública em 11.12.2015, Poder Executivo, Brasília, DF, 9 dez. 2015.

BRASIL. Conselho Nacional de Educação. Resolução nº 2 , de $1^{\circ}$ de julho de 2015. Define as Diretrizes Curriculares Nacionais para a formação inicial em nível superior (cursos de licenciatura, cursos de formação pedagógica para graduados e cursos de segunda licenciatura) e para a formação continuada. Diário Oficial da República Federativa do Brasil, Poder Executivo, Brasília, DF, 02 jul. 2015.

BRASIL. Ministério da Saúde. Portaria $n^{\circ}$ 562, de 4 de abril de 2013. Define o valor mensal integral do incentivo financeiro do Programa Nacional de Melhoria do Acesso e da Qualidade da Atenção Básica (PMAQ-AB), denominado como Componente de Qualidade do Piso de Atenção Básica Variável (PAB Variável). Diário Oficial da República Federativa do Brasil, Poder Executivo, Brasília, DF, 05 abr. 2013b.

BRASIL. Ministério da Saúde. Portaria nº548, de 4 de abril de 2013. Define o valor de financiamento do Piso da Atenção Básica Variável para os Núcleos de Apoio à Saúde da Família (NASF) modalidade 1, 2 e 3. Diário Oficial da República Federativa do Brasil, Poder Executivo, Brasília, DF, 05 abr. 2013a. 
BRASIL. Casa Civil. Lei ${ }^{\circ} 12864$, de 24 de setembro de 2013. Altera o caput do art. $3^{\circ}$ da Lei n⿳ 8.080 , de 19 de setembro de 1990, incluindo a atividade física como fator determinante e condicionante da saúde. Diário Oficial da República Federativa do Brasil, Poder Executivo, Brasília, DF, 25 set. 2013a.

BRASIL. Portaria No 2.681. Redefine o Programa Academia da Saúde no âmbito do Sistema Único de Saúde (SUS). Diário Oficial da República Federativa do Brasil, Poder Executivo, Brasília, DF, 7 nov. 2013d.

BRASIL. Ministério da Saúde. Portaria n³124 de 28 de dezembro de 2012. Redefine os parâmetros de vinculação dos Núcleos de Apoio à Saúde da Família (NASF). Modalidades 1 e 2 às Equipes Saúde da Família e/ou Equipes de Atenção Básica para populações específicas, cria a Modalidade NASF 3, e dá outras providências. Diário Oficial da República Federativa do Brasil, Poder Executivo, Brasília, DF, 31 dez. 2012.

BRASIL. Ministério da Saúde. Portaria n²488 de 21 de outubro de 2011. Aprova a Política Nacional de Atenção Básica, estabelecendo a revisão de diretrizes e normas para a organização da Atenção Básica, para a Estratégia Saúde da Família (ESF) e o Programa de Agentes Comunitários de Saúde (PACS). Diário Oficial da República Federativa do Brasil, Poder Executivo, Brasília, DF, 24 out. 2011.

BRASIL. Conselho Nacional de Educação. Câmara de Educação Superior. Resolução nº4, de 6 de abril de 2009. Dispõe sobre carga horária mínima e procedimentos relativos à integralização e duração dos cursos de graduação em Biomedicina, Ciências Biológicas, Educação Física, Enfermagem, Farmácia, Fisioterapia, Fonoaudiologia, Nutrição e Terapia Ocupacional, bacharelados, na modalidade presencial. Diário Oficial da República Federativa do Brasil, Poder Executivo, Brasília, DF, 07 abr.. 2009.

BRASIL. Ministério da Saúde. Portaria n.154, de 24 de janeiro de 2008. Diário Oficial da República Federativa do Brasil, Poder Executivo, Brasília, DF, 4 mar. 2008.

BRASIL. Resolução n.7, de 31 de março de 2004. Institui as Diretrizes Curriculares Nacionais para os cursos de graduação em Educação Física, em nível superior de graduação plena. Diário Oficial da República Federativa do Brasil, Poder Executivo, Brasília, DF, 5 abr. 2004.

BRASIL. Lei n. 9696, de $1^{\circ}$ de setembro de 1998. Dispõe sobre a regulamentação da Profissão de Educação Física e cria os respectivos Conselho Federal e Conselhos Regionais de Educação Física. Diário Oficial da República Federativa do Brasil, Poder Executivo, Brasília, DF, 2 set. 1998.

BRASIL. Resolução n. 218, de 6 de março de 1997. Reconhecimento de profissionais de saúde de nível superior. Diário Oficial da República Federativa do Brasil, Poder Executivo, Brasília, DF, 05 maio. 1997.

BRASIL. Casa Civil. Subchefia para Assuntos Jurídicos. Lei no 8080, de 19 de setembro de 1990. Dispõe sobre as condições para a promoção, proteção e recuperação da saúde, a organização e o funcionamento dos serviços correspondentes e dá outras providências. Diário Oficial da República Federativa do Brasil, Poder Executivo, Brasília, DF, 20 set. 1990. 
BRASIL. Resolução n. 03, 16 de junho de 1987. Fixa os mínimos de conteúdo e duração a serem observados nos cursos de graduação em Educação Física (Bacharelado e/ou Licenciatura Plena). Diário Oficial da República Federativa do Brasil, Poder Executivo, Brasília, DF, 10 set. 1987.

BRUGNEROTTO, F.; SIMÕES, R. Caracterização dos currículos de formação profissional em educação física: um enfoque sobre saúde. Physis - Revista de Saúde Coletiva, Rio de Janeiro, v.19, n.1, p. 149-172, jan./mar., 2009.

CARVALHO, Y. M.; CECCIM, R. B. Formação e educação em saúde: aprendizados com a saúde coletiva. In: CAMPOS, G.W.S. et al. (Orgs.). Tratado de saúde coletiva. 2.ed. São Paulo: Hucitec, 2013. p.137-170.

CASTIEL, L.D.; SILVA, P.R.V. A noção "estilo de vida" em Promoção da Saúde: um exercício crítico de sensibilidade epistemológica. In: BAGRICHEVSKY, M. et al. (Orgs.). A saúde em debate na Educação Física - volume 2. Blumenau: Nova Letra, 2006. p.67-92.

CECCIM, R.B.; FEUERWERKER, L.C.M. Mudança na graduação das profissões de saúde sob o eixo da integralidade. Cadernos de Saúde Pública, Rio de Janeiro, v.20, n.5, p.14001410, set./out., 2004.

COSTA, L.C. et al. Formação profissional e produtividade em saúde coletiva do profissional de educação física. Revista Brasileira de Atividade Física e Saúde, Pelotas, v.17, n.2, p.107-113, abr., 2012.

COUTINHO, S.S. Competências do profissional de educação física na atenção básica à Saúde. 2011. 207f. (Doutorado em Saúde Pública)-Escola de Enfermagem. Universidade de São Paulo, Ribeirão Preto, 2011.

FALCI, D.M.; BELISÁRIO, S.A. A inserção do profissional de Educação Física na atenção primária à saúde e os desafios em sua formação. Interface - Comunicação, Saúde e Educação, Botucatu, v. 17, n.47, p.885-899, dez., 2013.

FERLA, A.A.; BUENOS, A.; SOUZA, R. Educação Física \& Saúde Coletiva: o que pode a ideia de integralidade na produção de mudanças no trabalho e na educação dos profissionais? In: FRAGA, A.B.; CARVALHO, Y.M.; GOMES, I.M. (Orgs.). As práticas corporais no campo da saúde. São Paulo: Hucitec, 2013. p.198-226.

FERREIRA, S.E. et al. Formação profissional em Educação Física e Saúde na Universidade Federal de São Paulo. Revista Brasileira de Atividade Física e Saúde, Pelotas, v.18, n.5, p.646-651, set., 2013.

FLORINDO, A. A. et al. Formação em educação física: o exemplo do curso de Ciências da Atividade Física da Universidade de São Paulo. In: NASCIMENTO, J. V. e FARIAS, G. O. (Orgs.). Construção da identidade profissional em educação física: da formação à intervenção. Florianópolis: UDESC, 2012. p.587-603.

FONSECA, S.A. et al. Pela criação da Associação Brasileira de Ensino da Educação Física para a Saúde: ABENEFS. Revista Brasileira de Atividade Física e Saúde, Pelotas, v.16, n.4, p.283-288, dez., 2011. 
GUARDA, F.R.B. et al. Caracterização das equipes do Programa Academia da Saúde e do seu processo de trabalho. Revista Brasileira de Atividade Física e Saúde, Pelotas, v.20, n.6, p.638-642, nov., 2015.

HADDAD, A.E. et al. Formação de profissionais de saúde no Brasil: uma análise no período de 1991 a 2008. Revista de Saúde Pública, São Paulo, v.44, n.3, p.383-393, jun., 2010.

PASQUIM, H. M. A Saúde Coletiva nos Cursos de Graduação em Educação Física. Saúde e Sociedade, São Paulo, v.19, n.1, p.193-200, mar., 2010.

PIZANI, J; RINALDI, I.P.B. Organização curricular dos cursos de educação física no Paraná: características da licenciatura e do bacharelado. Revista Educação Física-UEM, Maringá, v.25, n.1, p.95-108, 1.trim., 2014.

SÁ, G.B. et al. O Programa Academia da Saúde como estratégia de promoção da saúde e modos de vida saudáveis: cenário nacional de implementação. Ciência e saúde coletiva, Rio de Janeiro, v. 21, n. 6, p. 1849-1860, jun., 2016.

SANTIAGO, M.L.E.; PEDROSA, J.I.S.; FERRAZ, A.S.M. A formação em saúde à luz do Projeto Pedagógico e das Diretrizes Curriculares da Educação Física. Movimento, Porto Alegre, v.22, n.2, p.443-458, abr./jun., 2016.

SANTOS, S.F.S.; BENEDETTI, T.R.B. Cenário de implantação do Núcleo de Apoio a Saúde da Família e a inserção do profissional de Educação Física. Revista Brasileira de Atividade Física e Saúde, Pelotas, v.17, n.3, p.188-194, jun., 2012.

SOUZA, S.C.; LOCH, M.R. Intervenção do profissional de educação física nos Núcleos de Apoio à Saúde da Família em municípios do norte do Paraná. Revista Brasileira de Atividade Física e Saúde, Pelotas, v.16, n.1, p.5-10, 2011.

SOUZA NETO, S. et al. A formação profissional de educação física no Brasil: uma história sob a perspectiva da legislação federal do século XX. Revista Brasileira de Ciências do Esporte, Campinas, v.25, n.2, p.113-128, 2004.

Recebido em: 10/07/2016

Revisado em: 13/10/2016

Aprovado em: 14/10/2016

Endereço para correspondência:

rogerio.unifesp@gmail.com

Rogério Cruz Oliveira

Universidade Federal de São Paulo - Campus Baixada Santista.

Rua Silva Jardim 136, Vila Mathias, Santos-SP, Brasil. CEP: 11015-020 